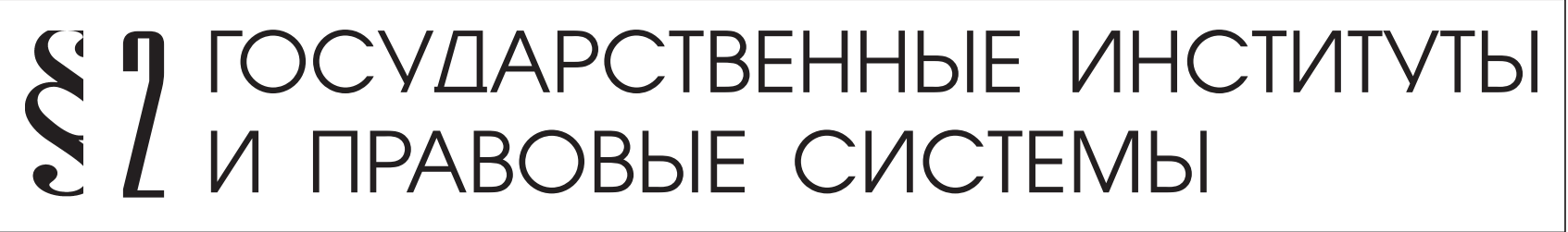

Антонова А.М.

\section{ОБЩАЯ ХАРАКТЕРИСТИКА ИЗБИРАТЕЛЬНОГО ЗАКОНОДАТЕЛЬСТВА РОССИИ И ТРЕХ СУБЪЕКТОВ ПРИВОЛЖСКОГО ФЕДЕРАЛЬНОГО ОКРУГА (РЕСПУБЛИКИ ТАТАРСТАН, РЕСПУБЛИКИ БАШКОРТОСТАН И САМАРСКОЙ ОБЛАСТИ)}

Аннотация: Предметом данного исследования стало избирательное законодательство нескольких субъектов Российской Федераиии Приволжского федерального округа, а именно : Республики Татарстан, Республики Башкортостан и Самарской области. В работе проводится сопоставление законов о выборах выше перечисленных субъектов Российской федераиии с нормами федерального избирательного законодательства. Более конкретно в статье представлен анализ особенностей построения избирательного законодательства Республики Татарстан, Республики Башкортостан и Самарской области. В работе также изучается и внутреннее содержание вымеуказанных норм права. Методологической основой исследования послужили различные методы научного познания, в частности, нами использовались методы сравнения, методы анализа и синтеза, системный метод. Особое значение уделялось использованию специальных методов: формально-юридическому и сравнительно-правовому Научная новизна исследования состоит в том, что данная работа является одной из первых в Российской Федерации, комплексно освещающих проблемы развития избирательного законодательства субъектов РФ в условиях реформирования федеративных отношений. Проведенное исследование позволяет определить современное состояние данного законодательства и его место в системе конституиионного законодательства РФ.По результатам проделанной работы сформулированы основные выводы, о том, что: региональное избирательное законодательство полностью соответствует федеральному законодательству по выборам; региональное избирательное законодательство постоянно усовершенствуется и соответствует политической обстановке в государстве; избирательное законодательство национальных государственных образований (республик) намного ближе по структуре и содержанию, чем с территориальными образованиями (края, области);в каждом рассматриваемом нами субъекте РФ имеются определенные особенности избирательного законодательства: в Республике Татарстан избирательное законодательство характеризуется детальностью и полнотой изложения избирательного процесса, избирательному законодательству Республики Башкортостан присуще простота изложения, в Самарской области свойственна сложность построения избирательного законодательства.Вне сомнений, тема изучения регионального избирательного законодательства требует дальнейшего исследования. Единственный вывод, который можно точно сделать по этой проделанной работе: региональное избирательное законодательство строится по принципу единообразия.

Ключевые слова: Выборы, федеральное избирательное законодательство, избирательная система, референдум, региональное избирательное законодательство, институты избирательного права, избирательные права граждан, губернатор, муниципальные выборы, принщип единообразия.

Abstract: This article presents a comparison of the electoral laws of the constituents of the Russian Federation with the federal electoral legislation. More specifically, the article presents the analysis of the peculiarities of the structure of electoral legislation of the Republic of Tatarstan, Republic of Bashkortostan, and Samara Oblast. The work examines the inner content of the above legal norms. The conducted research allows us to determine the present state of this legislation and its place within the system of constitutional legislation of the Russian Federation. As a result of the conducted research the author formulates the main conclusions of the following facts: - The regional electoral legislation fully complies with the federal electoral legislation; - The regional electoral legislation is constantly being improved and corresponds with the 
DOI: $10.7256 / 1811-9018.2015 .5 .11579$

При цитировании этой статьи сноска на dоі обязательна

\section{Право и политика 5 (185) $\bullet 2015$}

current political situation within the country;- The electoral legislation of the national government formations (republics) is much more similar in structure and content than that of the territorial formations (krai, oblast).

Keywords: Elections, Federal electoral legislation, Electoral system, Referendum, Regional electoral legislation, Electoral law institution, Passive electoral right, Governor, Municipal elections, Principle of uniformity.

Д вадцать лет со дня проведения выборов парламента - это важный итог в истории российского государства, свидетельствующий об окончательном повороте политической системы государства в направлении демократии, символ создания многопартийности.

В 2013 году избирательная система Российской Федерации отмечала свое 20 -летие. С принятием Конституции Российской Федерации были установлены основы демократизма, где единственным источником власти и носителем суверенитета признается народ. Высшей формой непосредственного выражения власти народа являются выборы или референдум. Путем выборов формируются федеральные органы государственной власти, органы государственной власти субъектов Федерации, органы местного самоуправления.

Ученые, сотрудничающие с Центральной избирательной комиссией Российской Федерации, давно проводят сравнительный анализ особенностей избирательных систем мира. Однако, по нашему мнению, необходимо проводить сравнительно-правовой анализ и регионального законодательства в России. Сравнительный анализ всегда продуктивен, поскольку позволяет выявить особенности, проблемы и достижения при организации и проведении выборов.

Избирательное законодательство субъектов Российской Федерации (далее субъектов РФ) представляет собой совокупность региональных нормативноправовых актов законодательного и подзаконного характера, регулирующих выборы в органы государственной власти субъектов РФ и муниципальные выборы.

Возглавляют избирательное законодательство субъектов РФ конституции республик, уставы областей, краев, автономной области и автономных округов, городов федерального значения. В отличие от Конституции Российской Федерации многие из региональных конституций и уставов содержат разделы об избирательной системе. Наличие таких разделов в основных законах субъектов РФ существенно повышает гарантированность избирательных прав граждан на уровне субъектов РФ, эффективность правоприменительной деятельности ${ }^{1}$.

1 Доклад Центральной Избирательной комиссии PФ // URL: http:// old.nasled.ru/analit/kapital/vybory1.htm\#M3
Основные источники избирательного права на региональном уровне можно подразделить на несколько групп: законы, отражающие порядок выборов в представительные (законодательные) органы субъектов РФ, законы, обеспечивающие регулирование выборов высших должностных лиц субъектов РФ, а также законы, регулирующие особенности проведения муниципальных выборов в субъектах РФ.

Избирательное законодательство субъектов РФ должно не противоречить федеральному законодательству по выборам. Это, прежде всего, нормам Конституции РФ и Федеральному закону «Об основных гарантиях избирательных прав и права на участие в референдуме граждан Российской Федерации»².

Следует обозначить структуру избирательного законодательства изучаемых субъектов Приволжского федерального округа. В Республике Татарстан избирательное право граждан регулируется Конституцией Республики Татарстан ${ }^{3}$, Избирательным кодексом Республики Татарстан ${ }^{4}$, Закона Республики Татарстан «О статусе депутата Государственного Совета Республики Татарстан» ${ }^{5}$, Закона Республики Татарстан « О народном обсуждении наиболее важных вопросов государственной жизни Республики Татарстан и местного значения» ${ }^{6}$.

На уровне Республики Башкортостан действуют следующие источники избирательного права:

\footnotetext{
2 Об основных гарантиях избирательных прав и права на участие в референдуме граждан Российской Федерации : федеральный закон от 12.06.2002 N 67-Ф3 (ред. от 21.02.2014). URL: http://www.consultant.ru (дата обращения : 20.03.2014)

${ }^{3}$ Конституция Республики Татарстан от 6 ноября 1992 г. (в ред. 14.12.2012). URL: http://www.consultant.ru (дата обращения: 20.03.2014)

${ }^{4}$ Избирательный кодекс Республики Татарстан от 7 мая 2007 г. N 21-3РТ (в ред. 28.10.2013). URL: http://www.consultant.ru (дата обращения : 20.03.2014)

${ }_{5}^{5}$ О статусе депутата Государственного Совета Республики Татарстан : закон Республики Татарстан от 18 марта 2004 года № 15-3РТ (в ред. 11.04.2013) // Справочно-правовая система «Консультант $+\gg .2014 .20$ марта

${ }^{6} \mathrm{O}$ народном обсуждении наиболее важных вопросов государственной жизни Республики Татарстан и местного значения: Закон Республики Татарстан от 6 августа 2003 г. N 26-3РТ (в ред. 15.12.2005). URL: http://www.consultant.ru (дата обращения: 20.03.2014)
} 
Конституция Республики Башкортостан ${ }^{7}$, Кодекс Республики Башкортостан о выборах 8 , Закон Республики Башкортостан «О Государственном Собрании - Курултае Республики Башкортостан»?

В Самарской области действует широкий перечень нормативно-правовых актов, регулирующие порядок проведения выборов в данном субъекте РФ, а именно: Устав Самарской области ${ }^{10}$, Закон Самарской области «О выборах Губернатора Самарской области»"1 «Об отзыве Губернатора Самарской области» ${ }^{12}$, Закон Самарской области «О выборах депутатов Самарской Губернской Думы» ${ }^{13}$, Закон Самарской области «О выборах главы муниципального образования, другого выборного должностного лица местного самоуправления» ${ }^{14}$, Закон Самарской области « О выборах депутатов представительного органа муниципального образования» ${ }^{15}$, Закон Самарской области «Об Избирательной комиссии Самарской области» ${ }^{16}$, Закон Самарской области «О гарантиях равенства политических партий при освещении их

\footnotetext{
${ }^{7}$ Конституция Республики Башкортостан от 24 декабря 1993 г. N BC-22/15 (в ред. 28.06.2012). URL: http://www.consultant.ru (дата обращения : 20.03.2014)

${ }^{8}$ Кодекс Республики Башкортостан о выборах от 6 декабря 2006 № 380 - 3 (в ред. 29.05.2013).URL:http://www.cikrb.ru/upload/iblock/ cad $/ \%$ D0\%9A $\%$ D0\%BE\%D0\%B4\%D0\%B5\%D0\%BA\%D1\%81\%20 $\% \mathrm{D} 0 \% \mathrm{~A} 0 \% \mathrm{D} 0 \% 91 \% 2005.06 .2013 . \mathrm{pdf}$

${ }^{9}$ О Государственном Собрании - Курултае Республики Башкортостан: закон Республики Башкортостан от 30 декабря 2002 г. N 448-з (в ред. 28.06.2012). URL: http://www.cikrb.ru/upload/ iblock/962/448c\%20emfyt $\% 20 i \% 20$ hjebnrxwxpp.pdf

${ }^{10}$ Устав Самарской области от 18 декабря 2006 года N 179-ГД (в ред.10.10.2012). URL: http://samara.izbirkom.ru/way/941064.html

${ }^{11}$ О выборах Губернатора Самарской области : закон Самарской области от 14 июня 2012 г. N 55-ГД (в ред.06.06.2013). URL: http:// samara.izbirkom.ru/way/941064.html

${ }^{12}$ Об отзыве Губернатора Самарской области : закон Самарской области от 10 октября 2012 г. N 95-ГД (в ред.06.06.2013). URL: http://samara.izbirkom.ru/etc/95_gd.rtf

${ }^{13} \mathrm{O}$ выборах депутатов Самарской Губернской Думы : закон Самарской области от 10 июля 2003 г. N 64-ГД (в ред.06.06.2013). URL: http://samara.izbirkom.ru/etc/64_gd.rtf

${ }^{14} \mathrm{O}$ выборах главы муниципального образования, другого выборного должностного лица местного самоуправления : закон Самарской области от 10 декабря 2003 г. N 112-ГД (в ред.06.06.2013). URL: http://samara.izbirkom.ru/etc/112_gd.rtf

${ }^{15} \mathrm{O}$ выборах депутатов представительного органа муниципального образования : закон Самарской области от 8 июня 2006 г. N 57-ГД (в ред.06.06.2013). URL: http://samara.izbirkom.ru/etc/57_gd.rtf

16 Об Избирательной комиссии Самарской области : закон Самарской области от 13 марта 2001 г. (в ред.06.06.2013). URL: http://samara.izbirkom.ru/etc/23-ГД_1.rtf
}

деятельности областными государственными телеканалами и радиоканалами» ${ }^{17}$.

Во всех трех изучаемыми нами субъектах РФ имеются отдельные законы, регламентирующие порядок проведения референдума в пределах их территорий и местного референдума.

Согласно ст.32 Конституции РФ граждане РФ имеют право участвовать в управлении делами государства как непосредственно, так и через своих представителей.

2. Граждане РФ имеют право избирать и быть избранными в органы государственной власти и органы местного самоуправления, а также участвовать в референдуме.

3. Не имеют права избирать и быть избранными граждане, признанные судом недееспособными, а также содержащиеся в местах лишения свободы по приговору суда.

Аналогично сформулировано избирательное право граждан в ст.45 Конституции Республики Татарстан ${ }^{18}$. Весьма скромно обозначено избирательное право граждан в ст.33 Конституции Республики Башкортостан ${ }^{19}$ и ст.11 Устава Самарской области ${ }^{20}$. Данные статьи имеют отсылочный характер на нормы Конституции РФ, федерального законодательства и законодательства субъекта РФ по вопросам выборов.

Избирательная система и избирательное право РФ базируется на основных гарантиях избирательных прав граждан РФ, обеспечивающих свободное волеизъявление граждан на выборах. Ядром этих гарантий являются принципы проведения выборов в России.

Граждане РФ участвуют в выборах на основе всеобщего равного и прямого избирательного права при тайном голосовании.

Принципы проведения в Российской Федерации выборов и референдума в субъектах РФ детально отрегулировано в республиканских кодифицированных актах по выборам. Наиболее приближены по оформлению и содержанию к нормам Федерального закона «Об основ-

\footnotetext{
${ }^{17} \mathrm{O}$ гарантиях равенства политических партий при освещении их деятельности областными государственными телеканалами и радиоканалами : закон Самарской области от 15 октября 2010 года N 109-ГД (в ред. 3.10.2013). URL: http://samara.izbirkom.ru/ etc/109_gd.rtf

${ }^{18}$ Конституция Республики Татарстан от 6 ноября 1992 г. (в ред. 14.12.2012). URL: http://www.consultant.ru (дата обращения : 20.03.2014)

${ }^{19}$ Конституция Республики Башкортостан от 24 декабря 1993 г. N BC-22/15 (в ред. 28.06.2012). URL: http://www.consultant.ru (дата обращения : 20.03.2014)

20 Устав Самарской области от 18 декабря 2006 года N 179-ГД (в ред.10.10.2012). URL: http://samara.izbirkom.ru/way/941064.html
} 


\section{Право и политика 5 (185) • 2015}

ных гарантиях избирательных прав и права на участие в референдуме граждан Российской Федерации» нормы Кодекса Республики Башкортостан о выборах. В указанном нормативно-правовом акте, как и в федеральном законе, отдельно раскрываются основные принципы избирательного права граждан. Например, статья 4 Кодекса Республики Башкортостан о выборах предусматривает гражданам всеобее избирательное право, в статье 5 - равное избирательное право, в статье 6 - прямое избирательное право, а статье 7 указано, что «голосование на выборах является тайным, исключающим возможность какого-либо контроля за волеизъявлением гражданина» ${ }^{21}$.

Выше перечисленные принципы избирательного права граждан в Избирательном кодексе Республики Татарстан объединены в двух статьях (ст.3 и 4), но это нисколько не влияет на их содержание 22 . Данные нормы полностью соответствуют нормам федерального законодательства по выборам.

В связи с отсутствием в Самарской области кодифицированного нормативно-правового акта по выборам, принципы избирательного права граждан закреплены в отдельных законах Самарской области, а именно: в статье 4 «Основные принципы проведения выборов Губернатора» и 5 «Избирательные права граждан Российской Федерации на выборах Губернатора» Закона Самарской области «О выборах Губернатора Самарской области» $»^{23}$; статья 5 «Избирательное право» Закона Самарской области «О выборах депутатов Самарской Губернской Думы» ${ }^{24}$.

По федеральному избирательному законодательству и законодательству субъектов РФ предусмотрены ограничения пассивного избирательного права граждан. Не имеют права быть избранными граждане РФ:

а) осужденные когда-либо к лишению свободы за совершение тяжких и (или) особо тяжких преступлений, за исключением случаев, когда в соответствии с новым уголовным законом эти деяния не признаются тяжкими или особо тяжкими преступлениями;

\footnotetext{
${ }^{21}$ Кодекс Республики Башкортостан о выборах от 6 декабря 2006 № 380-3 (в ред. 29.05.2013).URL: http://www.cikrb.ru/upload/iblock/ cad/\%D0\%9A \%D0\%BE\%D0\%B4\%D0\%B5\%D0\%BA\%D1\%81\%20 \%D0\%A0\%D0\%91\%2005.06.2013.pdf

${ }^{22}$ Избирательный кодекс Республики Татарстан от 7 мая 2007 г. N 21-3РТ (в ред. 28.10.2013). URL: http://www.consultant.ru (дата обращения : 20.03.2014)

${ }^{23} \mathrm{O}$ выборах Губернатора Самарской области : закон Самарской области от 14 июня 2012 г. N 55-ГД (в ред.06.06.2013). URL: http:// samara.izbirkom.ru/way/941064.html

${ }^{24}$ О выборах депутатов Самарской Губернской Думы: закон Самарской области от 10 июля 2003 г. N 64-ГД (в ред.06.06.2013). URL: http://samara.izbirkom.ru/etc/64_gd.rtf
}

б) осужденные за совершение преступлений экстремистской направленности, и имеющие на день голосования на выборах неснятую и непогашенную судимость за указанные преступления;

в) подвергнутые административному наказанию за совершение административных правонарушений, предусмотренных статьями 20.3 и 20.29 Кодекса Российской Федерации об административных правонарушениях, если голосование на выборах состоится до окончания срока, в течение которого лицо считается подвергнутым административному наказанию;

г) в отношении которых вступившим в силу решением суда установлен факт нарушения ограничений, предусмотренных пунктом 1 статьи 56 Федерального закона «Об основных гарантиях избирательных прав и права на участие в референдуме граждан Российской Федерации», либо совершения действий, предусмотренных подпунктом «ж» пункта 7 и подпунктом «ж» пункта 8 статьи 76 Федерального закона «Об основных гарантиях избирательных прав и права на участие в референдуме граждан Российской Федерации», если указанные нарушения либо действия совершены до дня голосования на выборах в течение установленного законом срока полномочий органа государственной власти или органа местного самоуправления, в которые назначены выборы, либо должностного лица, для избрания которого назначены выборы ${ }^{25}$.

Однако первое ограничение избирательного права, связанное с запретом баллотироваться ранее осужденным лицами, должно быть изменено. 10 октября 2013 г. Конституционный Суд РФ признал продп. «а» п.3.2 статьи 4 Федерального закона «Об основных гарантиях избирательных прав и права на участие в референдуме граждан Российской Федерации» не соответствующий нормам Конституции РФ. По мнению судей Конституционного Суда РФ «действующее законодательство ограничивает пассивное избирательное право осужденных бессрочно и необратимо. Тем самым, по сути, они навсегда лишаются своего конституционного права. Столь суровая мера не может быть оправдана одним лишь наличием у гражданина судимости. Бессрочное ограничение избирательного права возможно лишь для осужденных на пожизненный срок. В иных случаях оно не соответствует Конституции РФ.

Оспариваемые нормы также не делают различий между реальным и условным наказанием, не учитыва-

\footnotetext{
25 Об основных гарантиях избирательных прав и права на участие в референдуме граждан Российской Федерации : федеральный закон от 12.06.2002 N 67-Ф3 (ред. от 21.02.2014). URL: http://www.consultant.ru (дата обращения : 20.03.2014
} 
ют срок лишения свободы, назначенный судом, характер и степень общественной опасности преступления. Тем самым, они не обеспечивают должной индивидуализации и дифференциации ограничений, что также не соответствует Конституции.

Конституционный Суд РФ указал федеральному законодателю на то, что сроки ограничения пассивного избирательного права осужденного должны соотноситься со сроками судимости в рамках Уголовного кодекса РФ. В исключительных случаях за отдельные преступления (вследствие повышенной степени их общественной опасности) могут быть установлены более продолжительные сроки ограничения в разумных пределах ${ }^{26}$.

В целом, избирательное законодательство изучаемых республик схоже по структуре. В данных субъектах имеются кодифицированные нормативно-правовое акты, которые детально регламентируют порядок проведения выборов. Например, в Избирательном кодексе Республики Татарстан обозначены общие положения избирательного права, регулируются вопросы порядка работы избирательных комиссий в республике, подробно расписаны стадии избирательного процесса. В особенной части Избирательного кодекса Республики Татарстан отрегулированы особенности проведения выборов в законодательный орган республики (Государственный Совет Республики Татарстан) и выборов президента Республики Татарстан. В рассматриваемом кодифицированном нормативно-правовом акте имеются положения, содержащие информацию о проведении муниципальных выборов. Аналогично построен по содержанию Кодекс о выборах Республики Башкортостан.

В Самарской области каждый институт избирательного права (институт выборов губернатора, институт выборов депутатов законодательного органа области, институт муниципальных выборов, институт референдума) регулируется отдельными законодательными актами. В Самарской области порядок проведения вы- боров в Самарскую Губернскую Думу рассматривается в отдельном законе Самарской области «О выборах депутатов Самарской Губернской Думы». А в изучаемых нами республиках избирательный процесс в основном одинаков как по проведению выборов в законодательный орган субъекта, так и по выборам президентов республик. Порядок осуществления избирательного процесса полностью отрегулирован в кодифицированных актах по выборам Республики Татарстан и Республики Башкортостан.

По результатам проделанной работы мы пришли к выводам, что региональное избирательное законодательство полностью соответствует федеральному законодательству по выборам;

1. региональное избирательное законодательство постоянно усовершенствуется и соответствует политической обстановке в государстве;

2. избирательное законодательство национальных государственных образований (республик) намного ближе по структуре и содержанию, чем с территориальными образованиями (края, области);

3. в каждом рассматриваемом нами субъекте РФ имеются определенные особенности избирательного законодательства: в Республике Татарстан избирательное законодательство характеризуется детальностью и полнотой изложения избирательного процесса, избирательному законодательству Республики Башкортостан присуще простота изложения, в Самарской области свойственна сложность построения избирательного законодательства.

Вне сомнений, тема изучения регионального избирательного законодательства требует дальнейшего исследования. Единственный вывод, который можно точно сделать по проделанной работе: региональное избирательное законодательство строится по принципу единообразия.

\section{Библиография:}

1. Любарев А.Е. Активность избирателей на федеральных, региональных и муниципальных выборах в Российской Федерации // NB: Проблемы общества и политики. - 2013. - 8. - C. 138-209. DOI: 10.7256/2306-0158.2013.8.8778. URL: http://www.e-notabene.ru/pr/article_8778.html

${ }^{26}$ По делу о проверке конституционности подпункта «а» пункта 3.2 статьи 4 Федерального закона «Об основных гарантиях избирательных прав и права на участие в референдуме граждан Российской Федерации», части первой статьи 10 и части шестой статьи 86 Уголовного кодекса Российской Федерации в связи с жалобами граждан Г.Б. Егорова, А.Л. Казакова, И.Ю. Кравцова, А.В. Куприянова, А.С. Латыпова и В.Ю. Синькова : Постановление Конституционного Суда РФ от 10.10.2013 N 20-П. URL: http://www. consultant.ru (дата обращения : 20.03.2014 


\section{Право и политика 5 (185) $\bullet 2015$}

2. Любарев А.Е. Пропорциональная и смешанная избирательные системы на региональных и муниципальных выборах в Российской Федерации: проблемы «сфабрикованного большинства» // NB: Вопросы права и политики. - $2013 .-8$. - C. 65-118. DOI: 10.7256/2305-9699.2013.8.9212. URL: http://www.e-notabene.ru/lr/article_9212.html

3. Любарев А.Е.. Соответствуют ли российские выборы своему конституционному предназначению // Право и политика. - 2013. - № 13. - C. 104-107. DOI: 10.7256/1811-9018.2013.13.10158.

4. Кравченко О.А.. Условия обеспечения конституционного принципа достоверности определения волеизъявления народа // Право и политика. - 2013. - № 11. - С. 104-107. DOI: 10.7256/1811-9018.2013.11.10047.

5. М.А. Риэккинен. Участие граждан в управлении государством: международно-правовой аспект // Право и политика. 2013. - № 1. - C. 104-107. DOI: 10.7256/1811-9018.2013.01.12.

6. Матрёнина К.Ю.. Применение комплексов обработки избирательных бюллетеней при голосовании: защита от фальсификации или скрытое средство для искажения результатов // Право и политика. - 2013. - № 11. - C. 104-107. DOI: 10.7256/1811-9018.2013.11.10101.

7. Матейкович М.С., Сучилин В.Н.. Избирательные органы в России: история и современность // Право и политика. -2013. - № 10. - C. 104-107. DOI: 10.7256/1811-9018.2013.10.9667.

8. Беляев А.Ю.. Закономерности избирательного процесса, их использование в исследовательской практике // Политика и Общество. - 2013. - № 6. - С. 104-107. DOI: 10.7256/1812-8696.2013.6.8052.

9. Косоруков А.А.. Новые медиа как инструмент политической трансформации в современном мире // Международные отношения. - 2013. - № 3. - С. 104-107. DOI: 10.7256/2305-560X.2013.3.7594.

10. А.С. Сафонова. Политическое сознание молодежи в выборном процессе (на примере г. Санкт-Петербурга) // Политика и Общество. - 2012. - № 10. - С. 104-107.

11. А. В. Игнатов. Шестое издание Руководства по наблюдению за выборами БДИПЧ ОБСЕ: на пути к реформе института международного наблюдения // Право и политика. - 2012. - № 9. - С. 104-107.

12. Ю. А. Головин. Защита политической системы Российской Федерации: теоретические и прикладные аспекты проблемы // Национальная безопасность / nota bene. - 2012. - № 3. - С. 104-107.

13. Ю. А. Головин. Публичная политика как пространство легитимации власти (на примере Ярославской области) // Политика и Общество. - 2012. - № 4. - С. 104-107.

14. В. В. Трофимов. Формы участия структур гражданского общества в правообразующих отношениях // Право и политика. - 2012. - № 3. - С. 104-107.

15. Кашкина Е.В., Воробьева Т.И.. Проблемы взаимодействия органов внутренних дел с избирательными комиссиями при подготовке и проведении выборов в Российской Федерации // Полицейская деятельность. - 2012. - № 1. - С. 104-107.

16. М. О. Гвоздева. Международный и российский опыт Интернет-голосования // Политика и Общество. - $2012 .-$ № 1. - C. 104-107.

17. Н. С. Урсу. Использование технологий политического манипулирования в СМИ в ходе кампании по выборам депутатов Государственной Думы VI созыва // Национальная безопасность / nota bene. - 2012. - № 1. - C. 104-107.

18. А. Е. Любарев. Системная взаимосвязь основных параметров пропорциональной избирательной системы // Право и политика. - 2011. - № 10. - С. 104-107

\section{References (transliterated):}

1. Lyubarev A.E. Aktivnost' izbiratelei na federal'nykh, regional'nykh i munitsipal'nykh vyborakh v Rossiiskoi Federatsii // NB: Problemy obshchestva i politiki. - 2013. - 8. - C. 138-209. DOI: 10.7256/2306-0158.2013.8.8778. URL: http://www.e-notabene. $\mathrm{ru} / \mathrm{pr} /$ article $8778 . \mathrm{html}$

2. Lyubarev A.E. Proportsional'naya i smeshannaya izbiratel'nye sistemy na regional'nykh i munitsipal'nykh vyborakh v Rossiiskoi Federatsii: problemy «sfabrikovannogo bol'shinstva» // NB: Voprosy prava i politiki. - 2013. - 8. - C. 65-118. DOI: 10.7256/23059699.2013.8.9212. URL: http://www.e-notabene.ru//r/article_9212.html

3. Lyubarev A.E.. Sootvetstvuyut li rossiiskie vybory svoemu konstitutsionnomu prednaznacheniyu // Pravo i politika. - 2013. - № 13. - S. 104-107. DOI: 10.7256/1811-9018.2013.13.10158.

4. Kravchenko O.A.. Usloviya obespecheniya konstitutsionnogo printsipa dostovernosti opredeleniya voleiz"yavleniya naroda // Pravo i politika. - 2013. - № 11. - S. 104-107. DOI: 10.7256/1811-9018.2013.11.10047.

5. M.A. Riekkinen. Uchastie grazhdan v upravlenii gosudarstvom: mezhdunarodno-pravovoi aspekt // Pravo i politika. - 2013. - № 1. - S. 104-107. DOI: 10.7256/1811-9018.2013.01.12.

6. Matrenina K.Yu.. Primenenie kompleksov obrabotki izbiratel'nykh byulletenei pri golosovanii: zashchita ot fal'sifikatsii ili skrytoe sredstvo dlya iskazheniya rezul'tatov // Pravo i politika. - 2013. - № 11. - S. 104-107. DOI: 10.7256/1811-9018.2013.11.10101.

7. Mateikovich M.S., Suchilin V.N.. Izbiratel'nye organy v Rossii: istoriya i sovremennost' // Pravo i politika. - 2013. - № 10. S. 104-107. DOI: 10.7256/1811-9018.2013.10.9667.

8. Belyaev A.Yu.. Zakonomernosti izbiratel'nogo protsessa, ikh ispol'zovanie v issledovatel'skoi praktike // Politika i Obshchestvo. - 2013. - № 6. - S. 104-107. DOI: 10.7256/1812-8696.2013.6.8052.

9. Kosorukov A.A.. Novye media kak instrument politicheskoi transformatsii v sovremennom mire // Mezhdunarodnye otnosheniya. - 2013. - № 3. - S. 104-107. DOI: 10.7256/2305-560X.2013.3.7594. 
DOI: $10.7256 / 1811-9018.2015 .5 .11579$

При цитировании этой статьи сноска на доі обязательна

Государственные институты и правовые системы

10. A.S. Cafonova. Politicheskoe soznanie molodezhi v vybornom protsesse (na primere g. Sankt-Peterburga) // Politika i Obshchestvo. - 2012. - № 10. - S. 104-107.

11. A. V. Ignatov. Shestoe izdanie Rukovodstva po nablyudeniyu za vyborami BDIPCh OBSE: na puti k reforme instituta mezhdunarodnogo nablyudeniya // Pravo i politika. - 2012. - № 9. - S. 104-107.

12. Yu. A. Golovin. Zashchita politicheskoi sistemy Rossiiskoi Federatsii: teoreticheskie i prikladnye aspekty problemy // Natsional'naya bezopasnost' / nota bene. - 2012. - № 3. - S. 104-107.

13. Yu. A. Golovin. Publichnaya politika kak prostranstvo legitimatsii vlasti (na primere Yaroslavskoi oblasti) // Politika i Obshchestvo. - 2012. - № 4. - S. 104-107.

14. V. V. Trofimov. Formy uchastiya struktur grazhdanskogo obshchestva v pravoobrazuyushchikh otnosheniyakh // Pravo i politika. - 2012. - № 3. - S. 104-107.

15. Kashkina E.V., Vorob'eva T.I.. Problemy vzaimodeistviya organov vnutrennikh del s izbiratel'nymi komissiyami pri podgotovke i provedenii vyborov v Rossiiskoi Federatsii // Politseiskaya deyatel'nost'. - 2012. - № 1. - S. 104-107.

16. M. O. Gvozdeva. Mezhdunarodnyi i rossiiskii opyt Internet-golosovaniya // Politika i Obshchestvo. - 2012. - № 1. - S. 104-107.

17. N. S. Ursu. Ispol'zovanie tekhnologii politicheskogo manipulirovaniya v SMI v khode kampanii po vyboram deputatov Gosudarstvennoi Dumy VI sozyva // Natsional'naya bezopasnost' / nota bene. - 2012. - № 1. - S. 104-107.

18. A. E. Lyubarev. Sistemnaya vzaimosvyaz' osnovnykh parametrov proportsional'noi izbiratel'noi sistemy // Pravo i politika. 2011. - № 10. - S. 104-107 